\title{
Hair Dye poisoning - A rare case Report
}

N.S.Neki*, Ankur Jain, Rohit Bajaj, Mohit Manav Jindal

Department of Medicine, Govt. Medical College and Guru Nanak Dev Hospital, Amritsar, India

\section{DOI Name}

http://dx.doi.org/10.3126/jaim.v3i2.14069

\section{Keywords}

Paraphenylenediamine(PPD) poisoning;Toxic effects.

\section{Citation}

N.S.Neki, Ankur Jain, Rohit Bajaj, Mohit Manav Jindal. Hair Dye poisoning - A rare case Report. Journal of Advances in Internal Medicine 2014;03(01):72-73.

\begin{abstract}
Hair dye poisoning is not uncommon but an emerging entity in India with increased morbidity and mortality. The main component of hair dye poisoning is paraphenylenediamine(PPD), which is highly toxic thus making it life threatening. PPD poisoning can result in various toxic effects, multiorgan failure and ultimatetly death. Clinical suspicion and timely management can improve the outcome. We report a case of 35 year old male presented to hospital within 4 hours of consuming hair dye with complaints of swelling of face and neck, vomiting and difficulty in breathing. He was satisfactorily managed with supportive therapy and endotracheal intubation and discharged without any ill effects.
\end{abstract}

\section{INTRODUCTION}

Hair dye is available in powder and liquid forms and is not uncommon in India. It is freely available and cheap resulting in suicidal tendencies. Its main ingredient is derivative of paranitroaniline and is called paraphenylenediamine ${ }^{1}$ which after consumption can result in various systemic toxic effects in the form of angioneurotic edema, airway obstruction, hoarseness of voice, methemoglobinemia, gastritis, acute renal failure, rhabdomyolysis, hemolysis, myocarditis, multiorgan damage and death ${ }^{2,3}$

\section{CASE REPORT}

A 35 year old unemployed male was admitted in the emergency within 4 hours of consuming about $120 \mathrm{ml}$ of hair dye with complaints of swelling of face and neck, vomiting and difficulty in breathing. On examination he was semiconscious,
BP $110 / 70 \mathrm{~mm}$ of $\mathrm{Hg}$, Pulse rate $90 / \mathrm{min}$, oxygen saturation $90 \%$ with supplement oxygen and Respiratory rate 22/ min regular. Examination of respiratory, abdominal, CNS and cardiovascular system was normal. There was no cyanosis and jaundice. Laboratory investigations in the form of $\mathrm{Hb}, \mathrm{TLC}, \mathrm{DLC}$, RBS, B.urea, serum creatinine, sodium, potassium, calcium, phosphorus, SGOT, SGPT were within normal limits. ECG, X-ray chest, and 2D-Echo were normal. Colour of urine was dark brown suggestive of myoglobinuria. CPK level was 1230 which pointed towards rhabdomyolysis. In view of above findings, a diagnosis of life threatening anaphylaxis was made and patient was managed with endotracheal intubation. I.M. adrenaline

\footnotetext{
* Corresponding author N.S.Neki

Department of Medicine,

Govt. Medical College and Guru Nanak Dev Hospital,

Amritsar, India

Email:drneki123@gmail.com
} 
(1:1000), inj. Ceftriaxone, inj hydrocortisone $100 \mathrm{mg}$ 6hrly, inj ranitidine, inj avil and supportive therapy. The tracheostomy tube was removed on $4^{\text {th }}$ day with disappearance of edema and colour of urine and CPK level coming to normal. The patient was discharged in stable condition on $6^{\text {th }}$ day with an advice to consult Psychiatry department for counselling. Now he is on regular follow up with no fresh complaints.

\section{DISCUSSION}

The chemical PPD used in hair dye is brownish coloured solid, easily soluble in Hydrogen peroxide $\left(\mathrm{H}_{2} \mathrm{O}_{2}\right)$ but partially soluble in water and readily absorbed with mere dermal contact. It is metabolised to active radical by cytochrome $P_{450}$ peroxidase to form reactive benzoquinone diamine, which is further oxidised into Brandowaski's base. This base is extremely mutagenic and allergic ${ }^{2}$. First case of PPD poisoning was reported in the year 1924 in a hairdresser who was constantly exposed to this chemical ${ }^{4}$. Symptoms may appear in 4-6 hours of exposure as reported in this case. Various toxic effects could be related to oxidative stress ${ }^{5}$ skeletal and cardiac muscle necrosis ${ }^{2}$ as well as production of highly nephrotoxic quinone diamine resulting in acute renal failure and renal tubular obstruction ${ }^{6}$. Toxicities include angioedema of face, neck and tongue, dysphagia, slurring of speech, hoarseness of voice, methemoglobinemia, cardiac toxicity, rhabdomyolysis, acute renal failure, limbs edema, muscle tenderness, hepatitis, convulsions, hypotension, exopthalmos, blindness and sudden death $2,7,8$.

Hair poisoning is not commonly suicidal as in this case and may rarely be accidental or homicidal ${ }^{2}$. The angioedema of face, neck and tongue occurs due to allergic and hypersensitivity reaction along with increased permeability of mast cells while brown black colour of urine results from rhabdomyolysis. There is no specific antidote for PPD and treatment is mainly supportive ${ }^{4}$. Our patient was timely managed with adrenaline, antihistaminics, and endotracheal intubation. He recovered well without any sequale.

\section{CONCLUSION}

Hair dye poisoning is a life threatening emergency and is not uncommon in india unlike in the west. It requires emergency resuscitation and vigourous management of anaphylaxis. The main component of hair dye causing toxicity is Paraphenylenediamene(PPD) resulting in various manifestations. Although there is no specific antidote, timely intervention and supportive therapy can save the life of the patient.

\section{REFERENCES}

1. Bhargava P, Methew P. Hair dye poisoning J Asso Physicians India 2007;55:871-72

2. Jain PK, Agrawal N, Kumar P, Senger NS, Agrawal N, Akhtar N. Hair dye poisoning in Bundelkhand region. J Asso Physicians India 2011;59:415-19

3. Ashraf W, Dawling S, Farrow LJ. Systemic paraphenylenediamene poisoning: A case report and review. Hum Exp Toxicol 1994;13:167-70

4. Parveenkumar AS, Talari K, Dutta TK. Supervasomal hairs dye poisoning. Toxicol Int 2012;19:77-8

5. Chen $\mathrm{SC}$, Chen $\mathrm{CH}$, Tioh $\mathrm{YL}$, Zhong $\mathrm{PY}$, Lin $\mathrm{YS}$, Chye
SM. Paraphenylenediamine induced DNA damage and apoptosis through oxidative stress and enhanced caspases 8 and 9 activities in Mardin- Darby canine kidney cells. Toxicol in vitro2010;24:1197-202

6. Hummdi LA. Histopathological alteration of renal tubules of female rats typically treated with paraphenylenediamine. World Appl Sci J 2012;16;16:376-88

7. Lava NS, Dollar. Hair dye induced rhabdomyolysis J Electroencephalogr Clin Neurophysiol 1996;98:18

8. Prabhakar Y, Kamlakar K. Hair dye poisoning : A case report of three cases. J Dr NTR Univ Health Sci 2012;1:46-8 